\title{
Reconstruction of regional mean sea level anomalies = from tide gauges using neural networks
}

Manfred Wenzel, ${ }^{1}$ and Jens Schröter, ${ }^{1}$

J. Schröter, Alfred-Wegener-Institute, Bussestr. 24, 27570 Bremerhaven, Germany. (jens.schroeter@awi.de)

M. Wenzel, Alfred-Wegener-Institute, Bussestr. 24, 27570 Bremerhaven, Germany. (manfred.wenzel@awi.de)

${ }^{1}$ Alfred-Wegener-Institute, Bussestr. 24, 27570 Bremerhaven, Germany. 
3 Abstract. The 20th century regional and global sea level variations are

${ }_{4}$ estimated based on long term tide gauge records. For this the neural network

${ }_{5}$ technique is utilized that connects the coastal sea level with the regional and

6 global mean via a non-linear empirical relationship. Two major difficulties

7 are overcome this way: the vertical movement of tide gauges over time and

8 the problem of what weighting function to choose for each individual tide

9 gauge record. Neural networks are also used to fill data gaps in the tide gauge

10 records, which is a prerequisite for our analysis technique. A suite of differ-

${ }_{11}$ ent gap filling strategies is tested which provides information about stabil-

12 ity and variance of the results.

${ }_{13}$ The global mean sea level for the period January 1900 to December 2006

${ }_{14}$ is estimated to rise at a rate of $1.56 \pm 0.25 \mathrm{~mm} / \mathrm{yr}$ which is reasonably con-

15 sistent with earlier estimates, but we do not find significant acceleration. The

${ }_{16}$ regional mean sea level of the single ocean basins show mixed long term be-

${ }_{17}$ haviour. While most of the basins show a sea level rise of varying strength

${ }_{18}$ there is an indication for a mean sea level fall in the Southern Indian Ocean.

${ }_{19}$ Also for the the tropical Indian and the South Atlantic no significant trend

${ }_{20}$ can be detected. Nevertheless, the South Atlantic as well as the tropical At-

${ }_{21}$ lantic are the only basins that show significant acceleration. On shorter timescales,

${ }_{22}$ but longer than the annual cycle, the basins sea level are dominated by os-

${ }_{23}$ cillations with periods of about 50 to 75 years and of about 25 years. Con-

${ }_{24}$ sequently we find high (lagged) correlations between the single basins. 


\section{Introduction}

${ }_{25}$ Global sea level rise is one of the major concerns in predicting climate and climate ${ }_{26}$ change for the decades to come. Projections for sea level rise have been compiled in the ${ }_{27}$ IPCC third assessment report [Church et al., 2001] and the more recent 4th report, AR4, ${ }_{28}$ [Bindoff et al., 2007]. But still predictions vary substantially. It is important first to 29 understand the magnitude of the past sea level change before we can reduce uncertainties so in the future development.

${ }_{31}$ In this paper we will address the development of the global and regional, i.e. ocean ${ }_{32}$ basin wide, sea level during the past century. For this purpose monthly mean tide gauge 3з data from the Permanent Service for Mean Sea Level (PSMSL) data base [Woodworth and

${ }_{34}$ Player, 2003] will be used. However, the question is how well tide gauge records describe ${ }_{35}$ regional or global sea level trends. The comparison of altimeter derived sea level change ${ }_{36}$ and that at tide gauges indicated that local changes from tide gauges appear to be larger. 37 In recent studies Holgate and Woodworth [2004], White et al. [2005] as well as Prandi et s8 al. [2009] emphasize the differences between the true global mean and the one estimated 39 from tide gauges.

40 Furthermore processes inside the solid Earth must be considered not only for correcting ${ }_{41}$ measurements but also for changes in the shape of the ocean. This leads to the problem of ${ }_{42}$ how to separate measured sea level change from local change of the reference system (i.e. ${ }_{43}$ land movement). Commonly vertical tide gauge movement is estimated by modelling of 44 the solid earth and its viscous response to past glaciation and mass loading distribution ${ }_{45}$ [e.g. Peltier, 2004]. Peltier's analysis is available for the whole globe which makes it 
46 attractive for use, but many other solutions of the Glacial Isostatic Adjustment (GIA)

${ }_{47}$ exist (e.g. Lambeck and Johnson [1998], Milne et al. [2001], Mitrovica [2003] or Hagedoorn

${ }_{48}$ et al. [2007]). Alternatively, measurements from the Global Positioning System (GPS) at

${ }_{49}$ or close to tide gauge locations can be used. This was done thoroughly by various authors

so like Teferle et al. [2006], Wöppelmann et al. [2007, 2009] or Schöne at al., [2009]. They

${ }_{51}$ all demonstrate local differences between the GIA and GPS solutions.

${ }_{52}$ The question of how to relate tide gauge records to the global sea level was studied by

${ }_{53}$ Church et al., [2004]. Only satellite altimetry can provide an almost global mean. Church

${ }_{54}$ et al., [2004] used tide gauge records for the last 50 years and related them to the sea level

${ }_{55}$ variability and trends measured by the TOPEX/Poseidon mission. The analysis for the

${ }_{56}$ period of satellite observations was extended to the past using an Empirical Orthogonal

57 Function (EOF) expansion technique. The EOF method assumes that covariances of the

${ }_{58}$ past signal were the same as observed at present. A veritable strength of this method is

${ }_{59}$ that the spatial and temporal distribution of tide gauges may change with time. It allowed

${ }_{60}$ the reconstruction of the sea level evolution on a spatial resolution of 1 degree globally

${ }_{61}$ for five decades. At selected tide gauges an impressive skill could be demonstrated. In a

${ }_{62}$ follow on publication Church and White [2006], CW06 hereafter, included more historic

${ }_{63}$ sea level records and extended the reconstruction back to 1870. CW06 also discuss the

${ }_{64}$ error bounds of the analysis and a possible acceleration of sea level rise. In order to

${ }_{65}$ relate the relative height of tide gauge locations, which is a difficult geodetic task, Church

${ }_{66}$ et al. [2004] as well as Church and White [2006] performed their analysis in the space

${ }_{67}$ of temporal sea level change and later integrated sea level change to sea level height.

${ }_{68}$ However, the problem of quality assessment of sea level reconstruction remains an issue. 
${ }_{69}$ One way can be comparing the results from alternative approaches because independent

${ }_{86}$ book of Haupt et al. [2009]. 
${ }_{91}$ designed for the purpose. However, again the vertical land movement contaminates any 92 estimate.

After a short introduction to neural networks in section 2 we will describe the data used

${ }_{94}$ in section 3. A first application of the neural network will be given in section 4 dealing

${ }_{95}$ with filling data gaps in the tide gauge records. Finally in section 5 a network will be

${ }_{96}$ applied to estimate the regional mean sea level and section 6 will give a short summary.

\section{The Neural Network}

A neural network is an artificial neural system, a computational model inspired by

${ }_{98}$ the notion of neurophysical processes. It consists of several processing elements called

99 neurons, which are interconnected with each other exchanging information. There are many different kinds of such neural networks which differ in the way the neurons are interconnected and in the way the single neurons behave. A detailed overview can be

111 to the output. To manage this, each neuron (including the bias) of one layer is connected

${ }_{112}$ to every neuron in the underlying layer. They are not interconnected within the layers 
${ }_{119}\left\{x_{i}\right\}$ can be described as:

$y_{k}=\mathcal{F}\left\{b_{k}+\sum_{i=1}^{N} W_{k, i} x_{i}\right\}$

$\vec{y}=\overrightarrow{b_{O}}+\mathbf{W}_{I O} \cdot \vec{x}+\mathbf{W}_{H O} \cdot \tanh \left\{\overrightarrow{b_{H}}+\mathbf{W}_{I H} \cdot \vec{x}\right\}$ 
${ }_{134}$ The amount of neurons in each layer will be chosen depending on the special task. Note

$E=\frac{1}{2} \sum_{m=1}^{M} \sum_{k=1}^{K}\left(y_{k}^{n e t}\left(\vec{x}_{m}^{d a t}\right)-y_{k, m}^{d a t}\right)^{2}$

${ }_{144}$ where the summations include all $K$ output neurons and all $M$ training pairs. To find 
${ }_{156}$ tion $E$ exist. To moderate the danger of getting trapped in one of these local minima

${ }_{157}$ Freeman and Skapura [1991] propose to enlarge the training data set by including exam-

${ }_{158}$ ples with noise added to the input. This procedure was successfully applied by Wenzel

${ }_{159}[1993]$ and we will follow this line in this paper.

Furthermore, the situation $M \ll N_{\text {par }}$ might lead to an overfitting of the neural network,

$R=\frac{1}{2}\left[C_{I O} \sum w_{I O}^{2}+C_{I H} \sum w_{I H}^{2}+C_{H O} \sum w_{H O}^{2}\right]$

\section{Data}

171

For our purpose we use monthly sea level data from tide gauges downloaded from the Permanent Service for Mean Sea Level (PSMSL) website [http://www.pol.ac.uk/psmsl] in June 2008. To avoid possible problems with the different local reference frames all computations will be done in the space of temporal derivatives, i.e. monthly differences.

. 
175 Beyond that, this makes the data more suitable for the BPN because it better limits the 


\section{Filling Data Gaps}

206 
${ }_{220}$ stepping operators. Both networks have the following dimension: 112 input, 84 hidden and

56 output neurons, i.e. there are 20524 parameters / weights to estimate. The networks are trained using all 297 examples that have three complete subsequent timesteps.

Following the suggestion of Freeman and Skapura [1991] examples with noise added to the input are included in the training to moderate the problem of getting trapped in local costfunction minima. Each of the original training examples is repeated three times with Gaussian noise added that corresponds to 5, 10 and 15\%, respectively, of the standard deviation estimated from all utilized tide gauge values.

To tackle the problem of overfitting, the ridge regression penalty (3) is included in the training of the networks. To find an appropriate value of $C_{r}$ we tested the values 0 to 50 in steps of 10. Figure 5 shows the dependence of the BCnet output error on the choice of $C_{r}$. Here the BCnet is applied recurrently starting from February, 2007 going backwards in time, i.e. data gaps at the input of the BCnet are filled using the output from the previous step(s). To start this time stepping procedure, data gaps at the very beginning are filled with values taken from the mean annual cycle. The benefits of (3) are obvious: Compared to not applying the ridge regression penalty $\left(C_{r}=0.0\right)$ the error of the network output is reduced by about $25 \%$ in unknown environments, i.e. for timesteps not used in the training phase (mainly before 1955), while the error gets only slightly worse for the training examples (the minimum values in Fig. 5 after 1955). There is only weak dependence on the actual value of $C_{r}$ but we found a slight minimum for $C_{r}=30$. A further increase of $C_{r}$ worsens the error again for untrained examples. Analogous results are found for the FCnet. This induces the final choice of $C_{r}=30$. 
256 points directly.

257 statistics.

As an example Fig. 6 shows the reconstructed sea level derivatives at the tide gauge Kwajalein (code 720011 , position: $8.73^{\circ} \mathrm{N} 167.73^{\circ} \mathrm{E}$ ) for the period $1940-1960$. Alternatively to using the FCnet and the BCnet recurrently (Fig. 6a) we also tested the combination of the neural network and the MAC/EOFR reconstruction, i.e. we filled the data gaps at the network input by taking values either from the MAC (Fig. 6b) or from the EOFR (Fig. 6c). All reconstructed time series reproduce the original data resonably well and have approximately the same error when compared to all known data points (Fig. 7). For both networks the RMS of the output error is lowest at the timesteps used for training. At untrained timesteps after 1940 it stays at the level of about 40\% the standard deviation estimated from the existing tide gauge data at the corresponding timestep. With the increasing number of data gaps before 1940 the error slightly rises to about $60 \%$. When filling the gaps with the MAC (Tab. 2, case 1 ) the error stays at the $60 \%$ level after 1940 and rises to about 100\% before (Fig. 7a). For EOFR (Tab. 2, case 2) the error appears much less because the EOF method minimizes the error at given data From these results it is hard to distinguish which reconstruction to prefer, and in the following we will treat all timeseries as an ensemble of possible realisations. The ensemble is enlarged by two further realisations: one takes the best of the single network reconstructions (Tab. 2, cases 3 to 8 ) at each timestep, i.e. the one with minimum error, and 1 the other is built as the error weighted mean of the these. Using this ensemble will allow us later on to account for the uncertainty in the reconstruction and to do some error 


\section{Regional Mean Sea Level}

\subsection{Reconstruction}

${ }^{264}$ The final purpose of this paper is to estimate the regional MSLA for the eight ocean regions that are indicated by color shading in Fig. 2. This will be done by using a neural ${ }_{266}$ network that is supplied with the monthly difference values from all selected tide gauges ${ }_{267}$ and gives the corresponding regional MSLA derivatives for all the ocean regions at once. This network will be denoted as TGRMnet in the following. Again we utilize a BPN of the same general configuration as in section 4. In this case the network has 56 input neurons, 270 i.e. one for each tide gauge, and eight output neurons, i.e. one for each ocean region. ${ }_{271}$ To complete the network layout there are 112 hidden neurons implemented. This finally ${ }_{272}$ gives 7736 connection weights to be estimated. Note that there is no extra output neuron ${ }_{273}$ for the global MSLA! Instead, the network training includes an additional constraint that ${ }_{274}$ minimizes the difference between the area weighted mean of the regional MSLA from the ${ }_{275}$ network and the corresponding given global value. Prior experiments have shown that ${ }_{276}$ this procedure results in more robust estimates because it interlinks the output neurons. The TGRMnet is trained using three alternatives of regional MSLA data: the corresponding values are computed either from the GFZ altimetry data (GFZ-training) or from ${ }_{279}$ the CSIRO dataset (CSIRO-training). In the third case we use both datasets simultaneously (CSIRO+GFZ-training), i.e. there are two different target values for the same BPN ${ }_{281}$ input. The temporal overlap with the tide gauges ranges from Jan.1993 to Jun.2005. Thus there are 148 basic examples available to train the network (this number doubles in case of the CSIRO+GFZ-training). As for the training of the FCnet and BCnet (section 4) we increased this number by adding training examples with noisy input to moderate the 
${ }_{285}$ problem of getting trapped in local costfunction minima. Using two different target val-

${ }_{286}$ ues for the same input as in the CSIRO+GFZ-training is somewhat like adding noise to

${ }_{287}$ the output too. This interpretation leads to a further difference in the BPN training as

${ }_{288}$ compared to the common standard: the misfit at the output neurons will be weighted

${ }_{289}$ according to the uncertainty of the training data, i.e. the final costfunction $E$ for the

290 TGRMnet is:

$$
\begin{aligned}
E_{m} & =\frac{1}{2} \sum_{k=1}^{K} r w_{k}\left(y_{k}^{n e t}\left(\vec{x}_{m}^{d a t}\right)-y_{k, m}^{d a t}\right)^{2} \\
& +\frac{1}{2} r w_{\text {glob }}\left[\left(\sum_{k=1}^{K} A_{k} y_{k}^{\text {net }}\left(\vec{x}_{m}^{d a t}\right)\right)-y_{\text {glob }, m}^{\text {dat }}\right]^{2} \\
E & =\sum_{m=1}^{M} E_{m}+R
\end{aligned}
$$

${ }_{291}$ where $\sum_{k}$ adds up the ocean regions and $A_{k}$ are the weights (relative areas of the ocean ${ }_{292}$ basins) to compute the global value from the regionals. $R$ is given by (3). The RMS of the difference between the GFZ and the CSIRO data (Tab. 1) give a reasonable approximation for the data uncertainty and the weights of the regional misfits, $r w_{k}$, are the squared inverse of the corresponding RMS values. They are applied for all three training datasets.

To estimate the weight $C_{r}$ of the ridge regression penalty (Eq. 3 and 4) we scanned 
304 Figure 8 shows the dependence of the cost $E_{m}(5)$, converted to a mean RMS error, on 
${ }_{327}$ Each member is then converted to regional MSLA by temporal integration, i.e. building

${ }_{328}$ the cumulative sum. An offset is added to all these regional MSLA curves to obtain a 329 zero temporal mean in 1993-2005.

\subsection{Discussion}

Figure 9 shows the resulting MSLA for the sub-ensembles of the CSIRO and GFZ trained networks, i.e. taking the results from all $C_{r}$ values and from all tide gauge reconstructions (=50 members), compared to the corresponding training data. The global ocean and the North Pacific are taken as examples. The training data are well reproduced by the TGRMnet although there are deviations noticeable especially for the global ocean (Fig. 9a). These are mainly caused by the apparent differences in the overall trends of the TGRMnet and the training data. However, the differences are smaller than those between the observations (Tab. 1, column diff). Furthermore, the maximum deviations from the corresponding data stay at or even below the the standard deviation of the difference between the two training data sets. Similar results are obtained for the regions not shown. Good agreement with the training data we find also for the amplitude and phase of the annual cycle. After high-pass filtering the MSLA timeseries (using a 1.5 years cut-off frequency) the amplitude and phase are estimated by fitting an annual sinusoid. To get an idea about its temporal variability this is done in a moving five year window. The agreement is demonstrated in Fig. 10 for the global ocean. As good or even better results are found for the single ocean basins.

First we looked at the dependence of the regional MSLA on the dataset chosen for training (Fig. 11). The interannual to multi-decadal variablity shows only minor dependence on the training data. The influence of the data is mainly noticeable in the mean trends 
${ }_{349}$ given in Tab. 3 (ensemble means and standard deviations). At the first glance there 
$1.8 \mathrm{~mm} / \mathrm{yr}$, respectively, wherein our estimate using only the GFZ trained networks $(1.39 \pm 0.30 \mathrm{~mm} / \mathrm{yr})$ corresponds better to the estimate of Wöppelmann et al. [2007] while the trend resulting from the CSIRO training $(1.68 \pm 0.16 \mathrm{~mm} / \mathrm{yr})$ fits better to CW06.

Within this range of values the estimate of J06 might be seen as an upper limit. For the period 1993-2002 Holgate and Woodworth [2004] found that during the 1990s the global coastal mean sea level derived from tide gauges increased faster than the global average sea level from altimetry. This finding was confirmed by White et al. [2005] for the 1990s and around 1970 based on the sea level reconstructions of Church et al. [2004]. However, White et al. [2005] did not find any significant difference between the globally averaged and the coastal sea level trend when looking at their full reconstruction period, 1950-2000.

Compared to the global mean the regional sea levels within the single ocean basins behave quite differently: In the Indian Ocean the tropical MSLA (Fig. 11b) is dominated by a multi-decadal oscillation with a rather positive mean trend $(0.65 \pm 0.81 \mathrm{~mm} / \mathrm{yr}$, Tab. 3) and negative acceleration $\left(-0.0094 \pm 0.0105 \mathrm{~mm} / \mathrm{yr}^{2}\right.$, Tab. 4) while it is the other way round for the Southern Indian Ocean (Fig. 11c) that shows a sea level fall ($0.59 \pm 0.72 \mathrm{~mm} / \mathrm{yr})$ and positive acceleration $\left(0.0064 \pm 0.0112 \mathrm{~mm} / \mathrm{yr}^{2}\right)$. In contrast to this difference in the very long timescale the shorter scales in these basins are well correlated. After eliminating the annual cycle and subtracting the corresponding quadratic regression lines from the sea level curves (Fig. 12a) the correlation is 0.6, with the Southern Indian Ocean leading by 14 months (Note: all correlations given hereafter are significant at the $99 \%$ level).

For the Pacific Ocean (Fig. 11d-f) the variations in the single sub-basins are even more similar. All basins show a distinct linear sea level rise with the highest rate in the northern 
${ }_{395}$ basin $(3.25 \pm 1.22 \mathrm{~mm} / \mathrm{yr})$ and the lowest in the southern $(1.23 \pm 0.66 \mathrm{~mm} / \mathrm{yr})$. None of the Pacific basins show significant acceleration. After subtracting the quadratic regression auto-correlation) for the North as well as for the tropical Pacific. The correlation among 
Beside these interbasin cross-correlations we also find good lag correlations at long timescales between the regional MSLA's and external indices, especially the Pacific Decadal Oscillation (PDO), that is the leading principal component of the monthly sea surface temperature (SST) anomalies in the North Pacific Ocean poleward of $20^{\circ} \mathrm{N}[\mathrm{Man}$ tua et al., 1997], and the Southern Annular Mode Index (SAM), which is defined as the difference in the normalized monthly zonal mean sea level pressure between $40^{\circ} \mathrm{S}$ and $70^{\circ} \mathrm{S}$ [Nan and Li, 2003]. The correlations with the PDO are e.g. -0.6 for the North Pacific, that leads the PDO by $\sim 9$ years, and -0.5 for the tropical Pacific, that lags by 26 years. Similar phase lags but with reduced correlations are obtained using the Interdecadal Pacific Oscillation Index (IPO; Parker et al. [2007]). Best correlations with the SAM ( 0.5) are found for the southern hemisphere ocean basins and for the global ocean. We also see similarities with the multidecadal SST modes derived by Mestas-Nuñez and Enfield [1999] especially for the North Atlantic (their Fig. 1) but also for the tropical Pacific (their Fig. 4) and the North Pacific (their Fig. 5). All this indicates the importance of the changes in ocean temperature as well as in ocean circulation (wind forcing) on the regional sea level. However, these are not the only influences. On regional scale the halosteric effects cannot be neglected (e.g. Wenzel and Schröter [2007]).

Finally, we look at the annual cycle of the regional MSLA. The good agreement between the TGRMnet results and the corresponding training data (Fig. 10) encourages us to look at the whole period from 1900 onward that is displayed in Fig. 13. The amplitudes of the annual cycle (Fig. 13a, b and c) show substantial temporal variations in the single ocean basins in dependence of its mean value. In contrast to this the phases (Fig. 13d, e and f) appear to be quite constant except for the tropical regions. Here the phase may 
${ }_{441}$ vary by up to 4 month (e.g tropical Pacific). The highest annual amplitudes are found for ${ }_{442}$ the northern hemisphere basins $(3.30 \pm 0.24 \mathrm{~cm}$ for the North Atlantic and $2.67 \pm 0.20 \mathrm{~cm}$

${ }_{443}$ for the North Pacific) with the maximum sea level appearing in late September, early

${ }_{444}$ October. Amongst the southern ocean basins the annual amplitudes appear to be more ${ }_{445}$ similar $(1.33 \pm 0.18 \mathrm{~cm}, 1.18 \pm 0.10 \mathrm{~cm}$ and $1.21 \pm 0.12 \mathrm{~cm}$ for the South Atlantic, Pacific and ${ }_{446}$ Indian Ocean, respectively) with the maximum sea level at the end of the austral summer.

${ }_{447}$ Furthermore we find phase differences among the southern basins: the South Pacific is ${ }_{448}$ lagging the Southern Indian Ocean and the South Atlantic by about 0.7 month and 4491.1 month, respectively. The lowest annual amplitudes are found for the tropical basins ${ }_{450}(0.56 \pm 0.11 \mathrm{~cm}, 0.18 \pm 0.08 \mathrm{~cm}$ and $0.45 \pm 0.11 \mathrm{~cm}$ for the tropical Atlantic, Pacific and ${ }_{451}$ Indian Ocean, respectively) and they are even lower for the global ocean $(0.24 \pm 0.03 \mathrm{~cm})$.

\section{Summary and Conclusions}

In this paper we demonstrated the feasibility and usefulness of neural networks within ${ }_{453}$ two different applications: filling data gaps in the tide gauge timeseries and in estimating ${ }^{454}$ the evolution of regional mean sea levels from these tide gauge data. First some general emarks about the networks: they are easy to use and appear to be an appropriate tool ${ }_{456}$ for the tasks in this paper, even though they have their disadvantages. In unknown ${ }_{457}$ environment, i.e. outside the training period, the behaviour of a neural network strongly ${ }_{458}$ depends on the way it has been trained, to what extent it has learned to generalize. This ${ }_{459}$ has been demonstrated in connection with both applications, the gap filling (section 4) as ${ }_{460}$ well as the reconstruction of the regional sea levels (section 5.1). To improve the quality of ${ }_{461}$ the network output it is recommended to use an ensemble of differently trained networks ${ }_{462}$ (e.g. Tangang et al. [1998]) and to take the mean afterwards. Further but usually minor 
${ }_{463}$ drawbacks are: neural networks are not very flexible, i.e. once they are trained the user

${ }_{464}$ is fixed to the chosen input / output configuration, and it is hard to impossible to learn

${ }_{465}$ from the network about e.g. the underlying mathematics or physics. For instance, one

${ }_{466}$ example for the latter is related to the GIA correction of the tide gauges. Although we

${ }_{467}$ applied this correction, it was not really necessary when estimating the regional MSLA

${ }_{468}$ from tide gauges. All computations are done in the space of temporal derivatives, i.e.

${ }_{469}$ monthly differences, and any additive correction to the input (tide gauge) signals needed,

${ }_{470}$ whether it stems from the global isostatic adjustment or from any other secular vertical

${ }_{471}$ land movement, would appear as a contribution to the bias of the hidden neurons. On

${ }_{472}$ the one hand this is an advantage of using the neural network, but on the other hand it is

${ }_{473}$ impossible to extract details about the correction made for a single tide gauge. Anyhow,

${ }_{474}$ another great advantage of the neural network is, that there is no need to determine the

${ }_{475}$ weighting of the individual tide gauges. The network learns during the training which

476 weights are appropriate. It also learns which tide gauge is most appropriate for which

477 ocean basin.

478 Information from 56 selected tide gauges are used to estimate the regional MSLA for

${ }_{479}$ the years 1900 to 2006. Although every tide gauge has more then 50 years of data, many

${ }_{480}$ values are missing, especially prior to 1950 (Fig. 3). This rapidly decreasing amount

${ }_{481}$ of direct information from the tide gauges back in time would cause problems for any

${ }_{482}$ method applied to estimate the mean sea level and result in increasing errors. In order

${ }_{483}$ to reduce these errors we first filled the data gaps in a reasonable way by neural networks

${ }_{484}$ that simulate the temporal evolution of all selected tide gauges at once by integrating

485 either forward or backward in time. 
${ }_{486}$ The reconstructed regional MSLA of the single ocean basins significantly differ in the

${ }_{487}$ long term behaviour that can be approximated by quadratic regression (see Tab. 3 and 4).

${ }_{488}$ While most of the basins show a sea level rise of different strength there is a mean sea level

${ }_{489}$ fall in the Southern Indian Ocean and no significant trend can be detected in the tropical

${ }_{490}$ Indian and the South Atlantic. Nevertheless, the South Atlantic as well as the tropical

${ }_{491}$ Atlantic are the only basins with significant acceleration. For the global mean sea level

${ }_{492}$ we estimate a trend of $+1.56 \pm 0.25 \mathrm{~mm} / \mathrm{yr}$. This value fits well to the earlier estimates

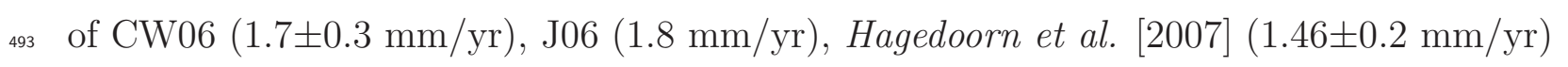

${ }_{494}$ or Wöppelmann et al. [2009] (1.61 $\left.\pm 0.19 \mathrm{~mm} / \mathrm{yr}\right)$. In contrast to CW06 or J06 we did

495 not find any significant acceleration in sea level rise. This is obviously due to the missing

496 depression in sea level prior to 1950 that is the main difference of our result to CW06 and 497 J06 (Fig. 11a).

${ }_{498}$ On medium timescales, i.e. after eliminating the annual cycle and subtracting the 499 quadratic regression, the estimated regional mean sea levels are dominated by oscillations ${ }_{500}$ with periods of about 50 to 75 years and $\sim 25$ years (the latter especially in the South ${ }_{501}$ Pacific). Consequently there are high phase lagged correlations among the basins. Good ${ }_{502}$ correlations also exist with external indices like the PDO and SAM. Furthermore, the ${ }_{503}$ timing of the annual maximum in the northern and southern ocean basins at the end of their hemispherical summer indicates the importance of the thermosteric contribution 505 to the (seasonal) sea level variation. This lets us conclude that the estimated variations ${ }_{506}$ show some realism. They are not only due to steric effects and/or the regional freshwater ${ }_{507}$ balance. There must also be periodic mass exchange between the single basins not only at seasonal periods [Stammer et al., 1996; Ponte, 1999] but also on longer time scales as 


\section{References}


Basis, Contributions of the Working Group I to the Third Assessment Report of the Intergovermental Panel on Climate Change [J. T. Houghton, Y. Ding, D.J. Griggs, M. Noguer, P. J. van der Linden and D. Xiaosu (Eds.)], Cambridge University Press, New York, pp. 641-684.

Church, J.A., N.J. White, R. Coleman, K. Lambeck, and J.X. Mitrovica (2004), Estimates of the Regional Distribution of Sea Level Rise over the 1950 to 2000 Period. J. Clim., $17,2609-2625$.

Church, J.A., and N.J. White (2006), A 20th century acceleration in global sea-level rise, Geophys. Res. Lett., 33, L01602, doi:10.1029/2005GL024826 .

Freeman, J.A., and D.M. Skapura (1991), Neural Networks - Algorithms, Applications and Programming Techniques, Addison-Wesley Publishing Company, Reading, MA, pp. 401. Gross, L., S. Thiria, and R. Frouin (1999), Applying artificial neural network methodology to ocean color remote sensing, Ecological Modelling, 120, 237-246, doi:10.1016/S03043800(99)00105-2 .

Hagedoorn, J.M., D. Wolf, and Z. Martinec (2007), An estimate of global mean sea-level rise inferred from tide-gauge measurements using glacial-isostatic models consistent with the relative sea-level record, Pure Appl. Geophys., 164, 791-818, doi:10.1007/s00024007-0186-7

Haupt, S.E., A. Pasini and C. Marzban (2009), Artificial Intelligence Methods in the Environmental Sciences, Springer Verlag, Berlin, Heidelberg, pp. 424

Holgate, S. J. (2007), On the decadal rates of sea level change during the twentieth century, Geophys. Res. Lett., 34, L01602, doi:10.1029/2006GL028492 
${ }_{552}$ Holgate, S.J., and P.L. Woodworth (2004), Evidence for enhanced coastal sea level rise during the 1990s, Geophys. Res. Lett., 31, L07305, doi:10.1029/2004GL019626

Hsieh, W.W., and B. Tang (1998), Applying Neural Network Models to Prediction and Data Analysis in Meteorology and Oceanography. Bull. Amer. Meteor. Soc., 79, 18551870.

Jevrejeva, S., A. Grinsted, J.C. Moore, and S. Holgate (2006), Nonlinear trends and multiyear cycles in sea level records, J. Geophys. Res., 111, C09012, doi:10.1029/2005JC003229

Jevrejeva, S., J.C. Moore, A. Grinsted, and P.L. Woodworth (2008), Recent global sea level acceleration started over 200 years ago?, Geophys. Res. Lett., 35, L08715, doi:10.1029/2008GL033611.

Lambeck, K., and P. Johnston (1998), The viscosity of the mantle: Evidence from analyses of glacial rebound phenonena. In: The Earth's Mantle [I. Jackson (Ed.)], Cambridge University Press, pp. 461-502.

Lee, T.L., and D.S. Jeng (2002), Application of artificial neural networks in tideforecasting, Ocean Engineering, 29, 1003-1022, doi:10.1016/S0029-8018(01)00068-3

Mantua, N.J., S.R. Hare, Y. Zhang, J.M. Wallace, and R.C. Francis (1997), A Pacific interdecadal climate oscillation with impacts on salmon production. Bull. Am. Meteorol. Soc., 78, 1069-1079.

Mestas-Nuñez, A.M., and D.B. Enfield (1999), Rotated Global Modes of Non-ENSO Sea Surface Temperature Variability. J. Clim., 12, 2734-2746.

Milne, G. A., J. L. Davis, J. X. Mitrovica, H.-G. Scherneck, J. M. Johansson, M. Vermeer, and H. Koivula (2001), Space-geodetic constraints on glacial isostatic adjustment in 
Fennoscandia. Science, 291, 2381-2385.

Mitrovica, J. X. (2003), Recent controversies in predicting post-glacial sea-level change. Quat. Sci. Rev., 22, 127-133.

Müller, M.D., A.K. Kaifel, M. Weber, S. Tellmann, J.P. Burrows, and D. Loyola (2003), Ozone profile retrieval from Global Ozone Monitoring Experiment (GOME) data using a neural network approach (Neural Network Ozone Retrieval System (NNORSY)), J. Geophys. Res., 108 (D16), 4497, doi:10.1029/2002JD002784

Nan, S., and J. Li (2003), The relationship between the summer precipitation in the Yangtze River valley and the boreal spring Southern Hemisphere annular mode, Geophys. Res. Lett., 30 (24), 2266, doi:10.1029/2003GL018381

Parker, D.B. (1985), Learning Logic, Technical Report TR-47, Center of Computational Research in Economics and Management Science, MIT, Cambridge, MA

Parker, D., C. Folland, A. Scaife, J. Knight, A. Colman, P. Baines, and B. Dong (2007), Decadal to multidecadal variability and the climate change background, J. Geophys. Res., 112 D18115, doi:10.1029/2007JD008411

Peltier, W.R. (2004), Global isostacy and the surface of the ice-age Earth: The ICE-5G (VM2) model and GRACE, Ann. Rev. Earth Planet. Sci., 32, 111-149, doi:10.1146/annurev.earth.32.082503.144359

Ponte, R. (1999), A preliminary model study of the large-scale seasonal cycle in bottom pressure over the global ocean, J. Geophys. Res., 104, 1289-1300.

Prandi, P., A. Cazenave, and M. Becker (2009), Is coastal mean sea level rising faster than the global mean? A comparison between tide gauges and satellite altimetry over 1993-2007, Geophys. Res. Lett., 36, L05602, doi:10.1029/2008GL036564. 
Schöne, T., N. Schön, and D. Thaller (2009), IGS tide gauge benchmark monitoring pilot project (TIGA), scientific benefits. J. Geod., 83, 249-261, doi 10.1007/s00190-008-0269$\mathrm{y}$

Stammer, D., R. Tokmakian, A. Semtner, and C. Wunsch (1996), How well does a 1/4 global circulation model simulate large-scale oceanic observations?, J. Geophys. Res., $101,25779-25811$.

Stepanov, V.N., and C.W. Hughes (2006), Propagation of signals in basin-scale ocean bottom pressure from a barotropic model, J. Geophys. Res., 111, C12002, doi:10.1029/2005JC003450

Stogryn, A.P., C.T. Butler, and T. J. Bartolac (1994), Ocean surface wind retrievals from special sensor microwave imager data with neural networks, J. Geophys. Res., 99 (C1), $981-984$.

Tangang, F.T., W.H. Hsieh, and B. Tang (1998), Forecasting regional sea surface temperatures in the tropical Pacific by neural network models, with wind stress and sea level pressure as predictors, J. Geophys. Res., 103 (C4), 7511-7522

Teferle, F.N., R.M. Bingley, S.D.P. Williams, T.F. Baker, and A.H. Dodson (2006) Using continuous GPS and absolute gravity to seperate vertical land movement and changes in sea-level at tide-gauges in the UK, Phil. Trans. R. Soc. A, 364, 917-930, doi:10.1098/rsta.2006.1746.

Wenzel, M. (1993), Neural networks, a tool for prediction?, Berichte aus dem Fachbereich Physik, Report 36, Alfred-Wegener-Institute, Bremerhaven, Germany, pp.28

Wenzel, M., and J. Schröter (2007), The global ocean mass budget in 1993-2003 estimated from sea level change, J. Phys. Oceanogr., 37(2), 203-213., doi:10.1175/JPO3007.1 
${ }_{621}$ Werbos, P. (1974), Beyond regression: New Tools for Prediction and Analysis in the ${ }_{622}$ Behavioral Science, Ph.D. thesis, Harvard, Cambridge, MA

${ }_{623}$ White, N.J., J.A. Church, and J.M. Gregory (2005), Coastal and global sea level rise for 1950 to 2000, Geophys. Res. Lett., 32, L01601, doi:10.1029/2004GL021391 
Table 1. Temporal RMS of the monthly differences for the regional mean sea level $[\mathrm{cm} / \mathrm{month}]$ derived from the GFZ and the CSIRO altimeter products. mean $=(\mathrm{GFZ}+\mathrm{CSIRO}) / 2$, diff $=$ $($ CSIRO-GFZ) and ratio $=$ diff $/$ mean. See Fig. 2 for regions.

\begin{tabular}{|c|c|c|c|c|c|}
\hline & \multicolumn{4}{|c|}{ dataset / signal RMS $[\mathrm{cm} /$ month $]$} & \\
region & GFZ & CSIRO & mean & diff & ratio \\
\hline trop. Indian & 0.310 & 0.248 & 0.280 & 0.175 & 0.63 \\
South & 0.493 & 0.504 & 0.499 & 0.162 & 0.32 \\
\hline North & 1.033 & 1.037 & 1.035 & 0.170 & 0.16 \\
trop. Pacific & 0.162 & 0.159 & 0.161 & 0.073 & 0.45 \\
South & 0.474 & 0.455 & 0.464 & 0.094 & 0.20 \\
\hline North & 1.250 & 1.240 & 1.245 & 0.171 & 0.14 \\
trop. Atlantic & 0.272 & 0.243 & 0.258 & 0.092 & 0.36 \\
South & 0.529 & 0.535 & 0.532 & 0.101 & 0.19 \\
\hline global ocean & 0.108 & 0.118 & 0.113 & 0.054 & 0.48 \\
\hline
\end{tabular}

Table 2. Methods used to fill data gaps in tide gauge records (see text for details)

\begin{tabular}{|l|l|}
\hline \multicolumn{1}{|c|}{ acronym } & \multicolumn{1}{|c|}{ method } \\
\hline 1: mac & mean annual cycle (MAC) \\
2: eof & EOF reconstruction (EOFR) \\
\hline 3: fc/recurr & FCnet, recurrent \\
4: fc/mac fill & FCnet with input gaps filled by MAC \\
5: fc/eof fill & FCnet with input gaps filled by EOFR \\
6: bc/recurr & BCnet, recurrent \\
7: bc/mac fill & BCnet with input gaps filled by MAC \\
8: bc/eof fill & BCnet with input gaps filled by EOFR \\
\hline 9: fc/bc best & best of 3 to 8 (minimal fore-/backcast error at known values) \\
10: fc/bc mean & error weighted mean of 3 to 8 \\
\hline
\end{tabular}


Table 3. The effect of the choice of training data set on the regional mean sea level trend for the period 1900-2006. Given are the ensemble mean and standard deviation of the trends resulting from all $C_{r}$ training values and applying the net to all tide gauge reconstructions (50 ensemble members). For the column mean the complete ensemble of trends (150 members) is taken into account. See Fig. 2 for regions.

Regional mean sea level trend , period: 1900-2006 [mm/yr]

\begin{tabular}{|c||r|r|r|r|}
\hline \multicolumn{1}{|c||}{ region } & \multicolumn{1}{c|}{ GFZ } & \multicolumn{1}{c|}{ CSIRO } & CSIRO+GFZ & \multicolumn{1}{c|}{ mean } \\
\hline trop. Indian & $1.30 \pm 0.55$ & $0.21 \pm 0.79$ & $0.45 \pm 0.63$ & $0.65 \pm 0.81$ \\
South & $-0.69 \pm 0.51$ & $-0.85 \pm 0.77$ & $-0.23 \pm 0.71$ & $-0.59 \pm 0.72$ \\
\hline North & $2.68 \pm 1.12$ & $3.62 \pm 1.14$ & $3.44 \pm 1.20$ & $3.25 \pm 1.22$ \\
trop. Pacific & $1.47 \pm 0.44$ & $2.64 \pm 0.35$ & $1.55 \pm 0.31$ & $1.89 \pm 0.65$ \\
South & $1.43 \pm 0.57$ & $0.85 \pm 0.60$ & $1.41 \pm 0.65$ & $1.23 \pm 0.66$ \\
\hline North Atlantic & $2.25 \pm 1.01$ & $3.86 \pm 0.89$ & $4.01 \pm 1.27$ & $3.70 \pm 1.11$ \\
trop. A.55 & $3.11 \pm 0.64$ & $2.17 \pm 0.58$ & $2.51 \pm 0.73$ \\
South & $-0.35 \pm 0.80$ & $0.26 \pm 0.61$ & $0.10 \pm 0.77$ & $0.00 \pm 0.77$ \\
\hline global ocean & $1.39 \pm 0.30$ & $1.68 \pm 0.16$ & $1.61 \pm 0.18$ & $1.56 \pm 0.25$ \\
\hline
\end{tabular}

Table 4. The effect of the choice of training data set on the regional mean sea level acceleration for the period 1900-2006. Given are the ensemble mean and standard deviation of the accelerations resulting from all $C_{r}$ training values and applying the net to all tide gauge reconstructions (50 ensemble members). For the column mean the complete ensemble of accelerations (150 members) is taken into account. See Fig. 2 for regions.

Regional mean sea level acceleration , period: 1900-2006 [mm/ $\left.\mathrm{yr}^{2}\right]$

\begin{tabular}{|c||r|r|r|r|}
\hline \multicolumn{1}{|c||}{ region } & \multicolumn{1}{c|}{ GFZ } & \multicolumn{1}{c|}{ CSIRO } & \multicolumn{1}{c|}{ CSIRO+GFZ } & \multicolumn{1}{c|}{ mean } \\
\hline trop. Indian & $-0.0135 \pm 0.0088$ & $-0.0015 \pm 0.0101$ & $-0.0131 \pm 0.0078$ & $-0.0094 \pm 0.0105$ \\
South & $-0.0025 \pm 0.0092$ & $0.0147 \pm 0.0088$ & $0.0071 \pm 0.0084$ & $0.0064 \pm 0.0112$ \\
\hline North & $-0.0007 \pm 0.0211$ & $-0.0186 \pm 0.0192$ & $-0.0150 \pm 0.0183$ & $-0.0114 \pm 0.0209$ \\
trop. Pacific & $-0.0047 \pm 0.0079$ & $-0.0050 \pm 0.0075$ & $-0.0069 \pm 0.0072$ & $-0.0056 \pm 0.0076$ \\
South & $0.0004 \pm 0.0123$ & $0.0036 \pm 0.0085$ & $0.0023 \pm 0.0113$ & $0.0021 \pm 0.0108$ \\
\hline North & $0.0197 \pm 0.0221$ & $0.0001 \pm 0.0185$ & $0.0085 \pm 0.0203$ & $0.0094 \pm 0.0218$ \\
trop. Atlantic & $0.0148 \pm 0.0097$ & $0.0105 \pm 0.0071$ & $0.0091 \pm 0.0072$ & $0.0115 \pm 0.0084$ \\
South & $0.0203 \pm 0.0136$ & $0.0247 \pm 0.0127$ & $0.0249 \pm 0.0114$ & $0.0233 \pm 0.0127$ \\
\hline global ocean & $0.0023 \pm 0.0049$ & $0.0018 \pm 0.0033$ & $0.0005 \pm 0.0044$ & $0.0016 \pm 0.0043$ \\
\hline
\end{tabular}



ocean. annual cycle.

\section{Figure captions:}

Figure 1. Layout of a backpropagation network (BPN) enriched by direct connections between the input and the output layer (indicated by the blue lines from the right).

Figure 2. The positions of the 56 selected tide gauges are marked by the red circles. The amount of monthly data available at these positions is indicated by the length of the corresponding vertical bars. The color shaded areas indicate the regions of interest in this paper.

Figure 3. Number of tide gauges with monthly data available.

Figure 4. Comparing the regional mean sea level anomaly (monthly differences) from the CSIRO (red) and the GFZ (green) dataset for (a) the tropical Pacific $\left(15^{\circ} \mathrm{S}-15^{\circ} \mathrm{N}\right)$ and (b) the global

Figure 5. RMS error of the resulting recurrent backcast as compared with existing tide gauge values in dependence of the chosen ridge regression weight $C_{r}$ (4). At each timestep the RMS values are normalized with the standard deviation of the corresponding known values, i.e. $Y=$ $\left[\sum\left(y_{k}^{n e t}-y_{k}^{d a t}\right)^{2} / \sum\left(y_{k}^{d a t}-\overline{y^{d a t}}\right)^{2}\right]^{1 / 2}$. For better readability all curve are filtered to exclude the

Figure 6. Example for the resulting gap filling at the tide gauge Kwajalein $\left(8.73^{\circ} \mathrm{N} 167.73^{\circ} \mathrm{E}\right.$, code 720011) using cases 1 to 8 from Table 2. The original data are shown in black.

Figure 7. RMS error of the resulting forecast (a) and backcast (b) as compared with existing tide gauge values. The error resulting from comparing the tide gauge data to the mean annual cycle are included in (a). The RMS values are normalized and filtered as in Fig. 5

Figure 8. Data part $E_{m}$ of the TGRMnet costfunction (5) converted to a mean RMS value in dependence of the chosen $C_{r}$ value and the six validation cases train 1 to train 6 . The periods with data not used for training in cases train 1 to 5 are marked on the uppermost axis. For train 
${ }_{657} 6$ the retained data are chosen randomly from the whole period. Straight lines represent the cost

from the training data and the dashed lines from the retained data. For comparison the data RMS and the data error (from Tab. 1) are included.

Figure 9. Reconstructed MSLA for the global ocean (a) and the North Pacific (b) resulting from the TGRMnet trained with CSIRO and with GFZ data compared to the training data (thin lines with marks). The mean from all $C_{r}$ values and all tide gauge gap filling cases (Table 2) are shown. The CSIRO curve are offset by an arbitrary value.

Figure 10. Amplitude (a) and phase (b) of the annual cycle for the global MSLA from the CSIRO and the GFZ trained TGRMnet compared to the corresponding altimetric data (thin lines with marks).

Figure 11. Regional MSLA for the different ocean regions (color shaded areas in Fig. 2) in dependence of the training data chosen for the network training. For each training dataset the mean of the corresponding regional MSLA sub-ensemble ( $5 C_{r}$ values times 10 tide gauge reconstructions) is shown. The black line and grey shading give the mean and standard deviation, respectively, of the complete ensemble (150 members). For the global ocean (a) the results from Church and White [2006] and from Jevrejeva et al. [2006] are included for comparison. NOTE: All curves are filtered before plotting to eliminate the annual cycle!

Figure 12. Ensemble mean regional sea level anomaly for the different ocean regions after removing the annual cycle and the quadratic regression. The global ocean and the Indian are shown in (a), the Pacific in (b) and the Atlantic in (c).

Figure 13. Amplitude (a, b, c) and phase (d, e, f) of the annual cycle for the regional MSLA: global ocean and Indian Ocean are given in (a) and (d), the Pacific is in (b) and (e) and the Atlantic in (c) and (f). Amplitude and phase are estimated by fitting an annual period sinusoid 
${ }_{680}$ to the high-passed filtered ensemble mean MSLA curves (150 members) within a moving 5 year ${ }_{681}$ window, wherein the corresponding values are given at its center. Phases are given as date of ${ }_{682}$ maximum value. 


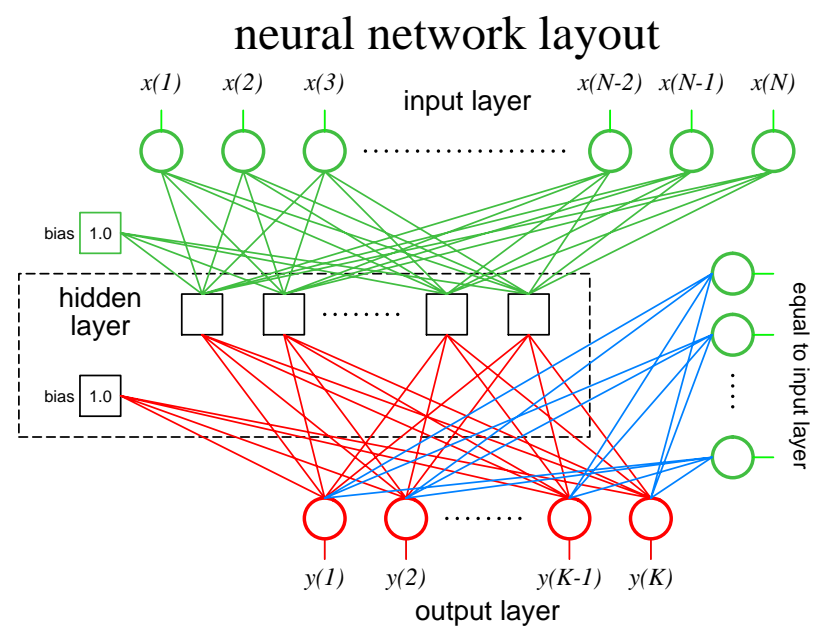

Figure 1. 


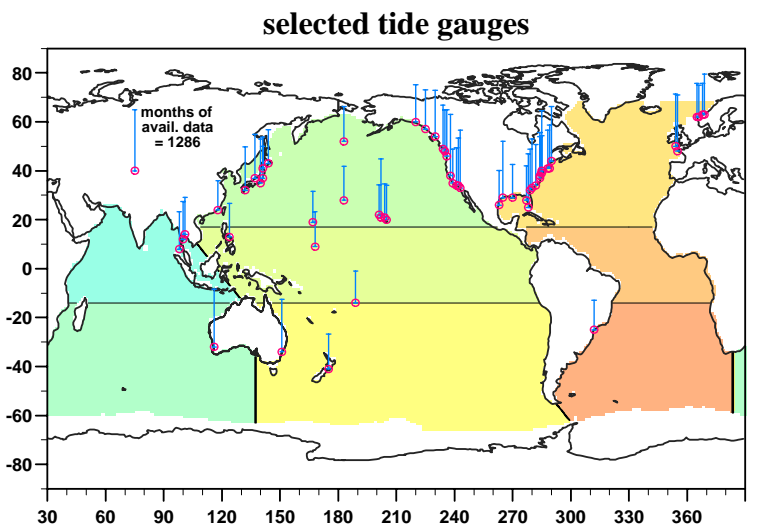

Figure 2.

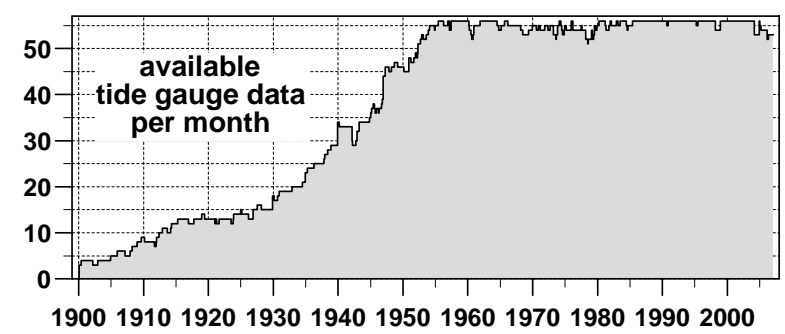

Figure 3.
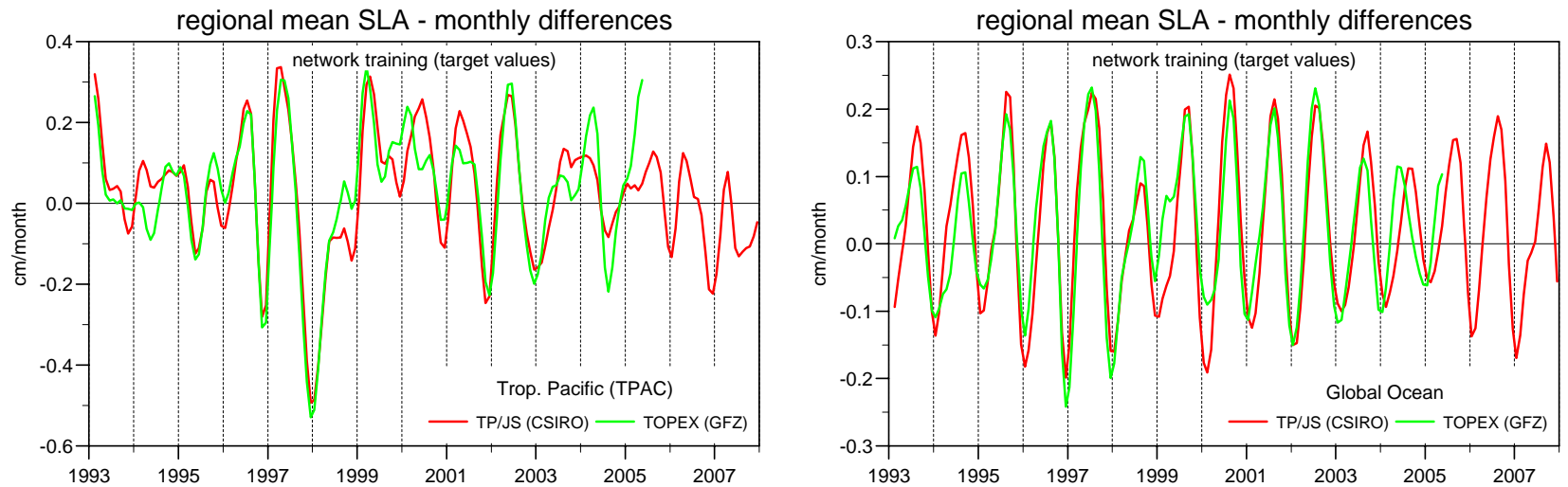

Figure 4.

D R A F T

January 11, 2010, 4:21pm

D R A F T 


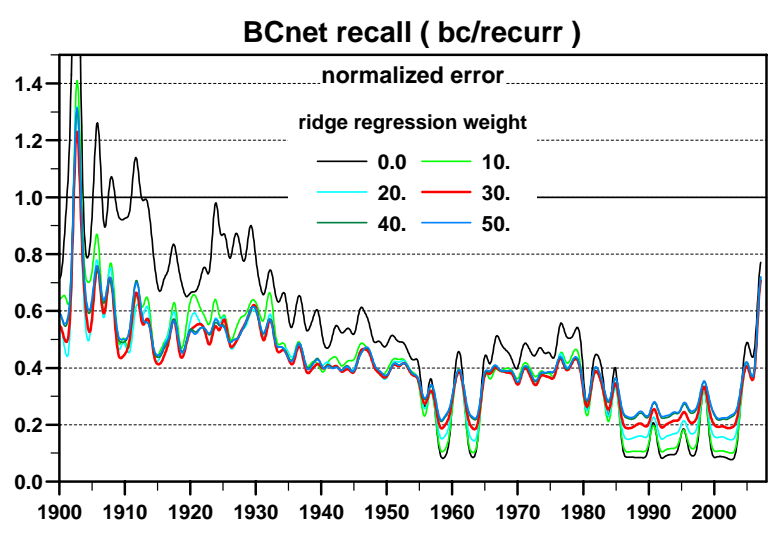

Figure 5.
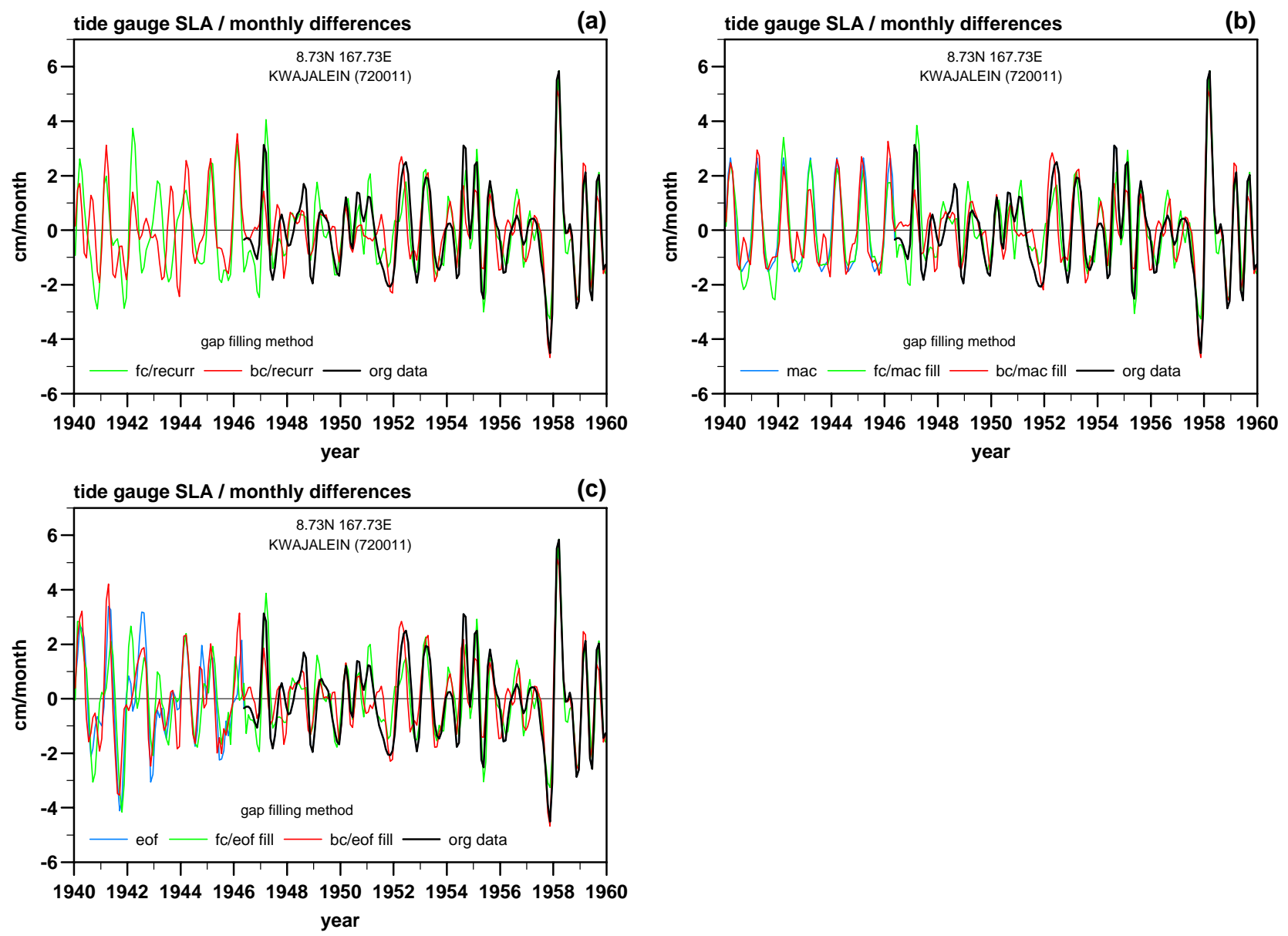

Figure 6. 
normalized network error

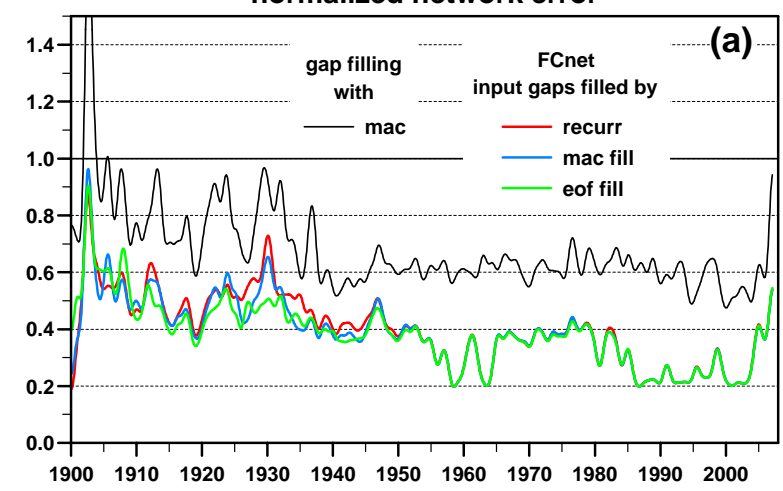

Figure 7.

CSIRO training

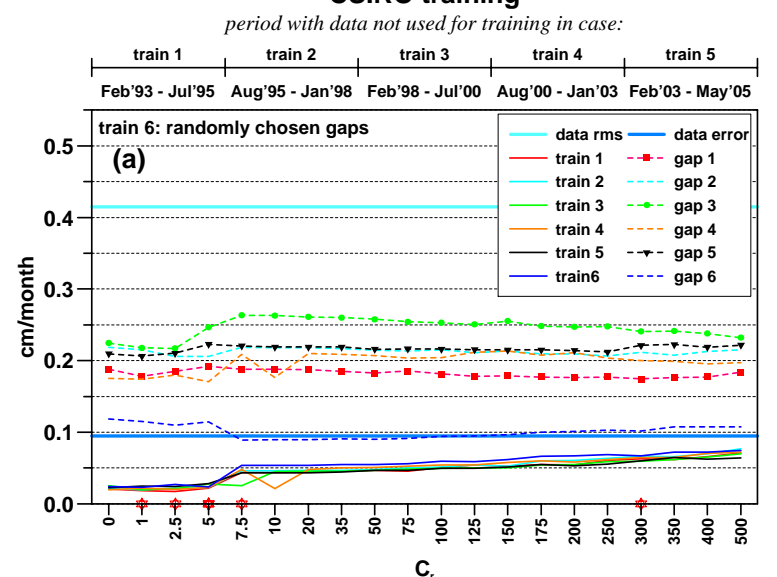

CSIRO+GfZ training

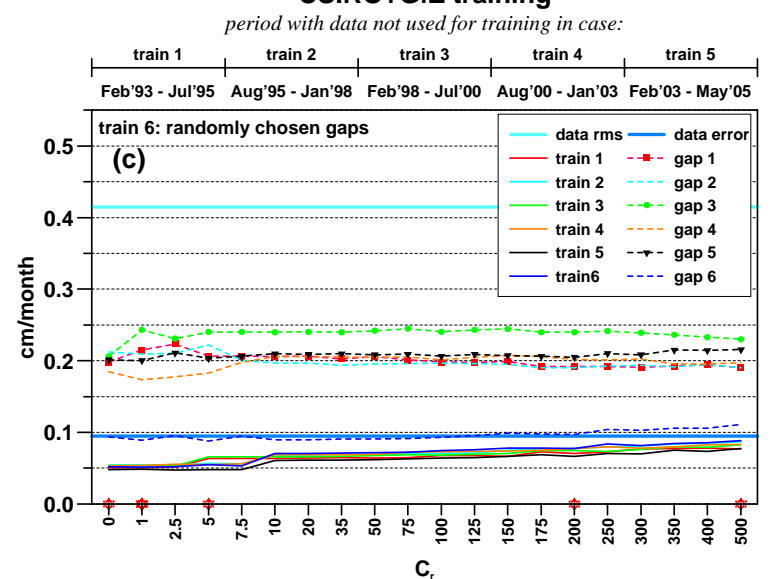

normalized network error

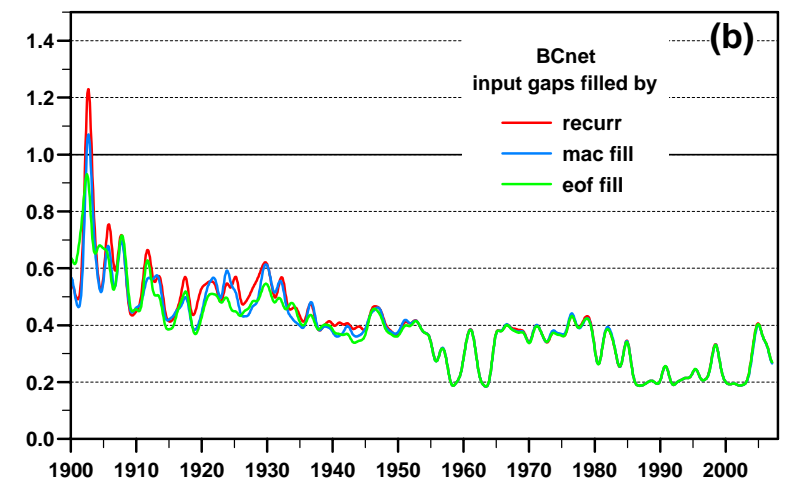

(b) 

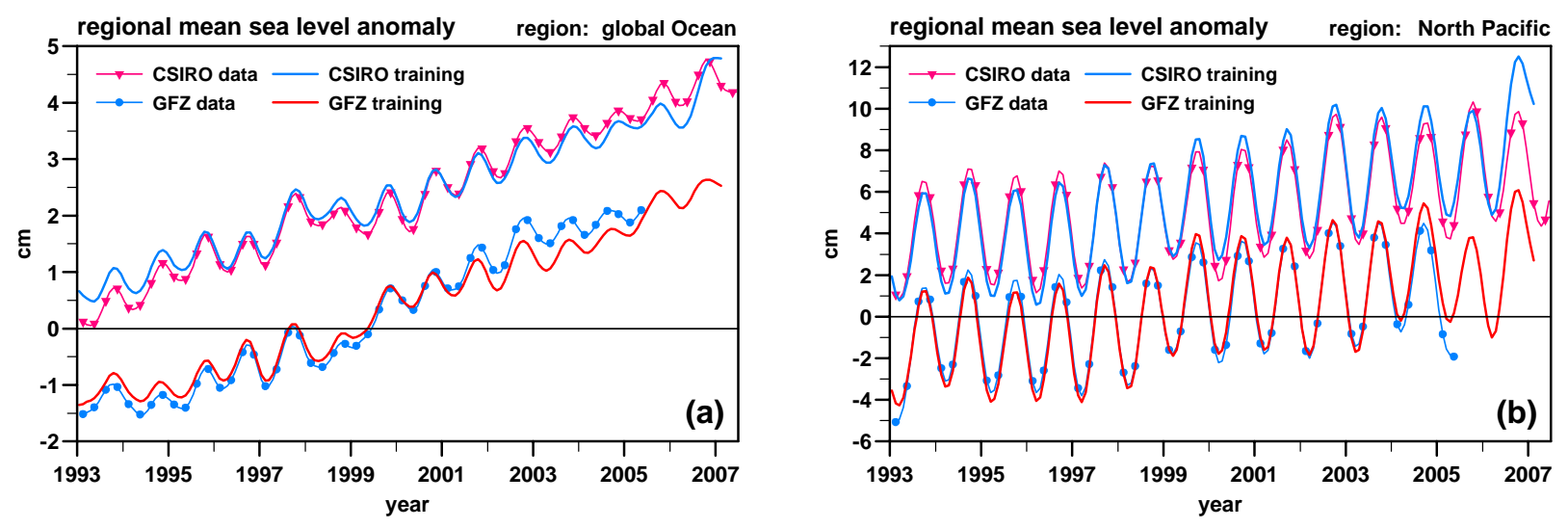

Figure 9.
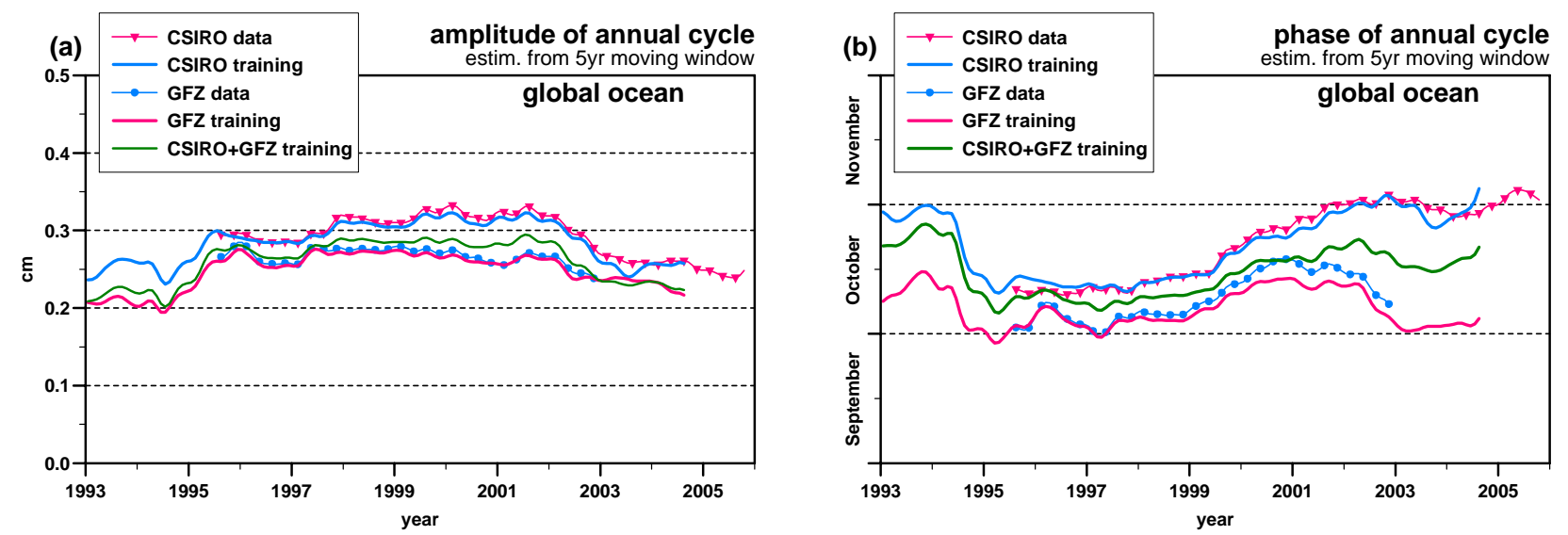

Figure 10. 

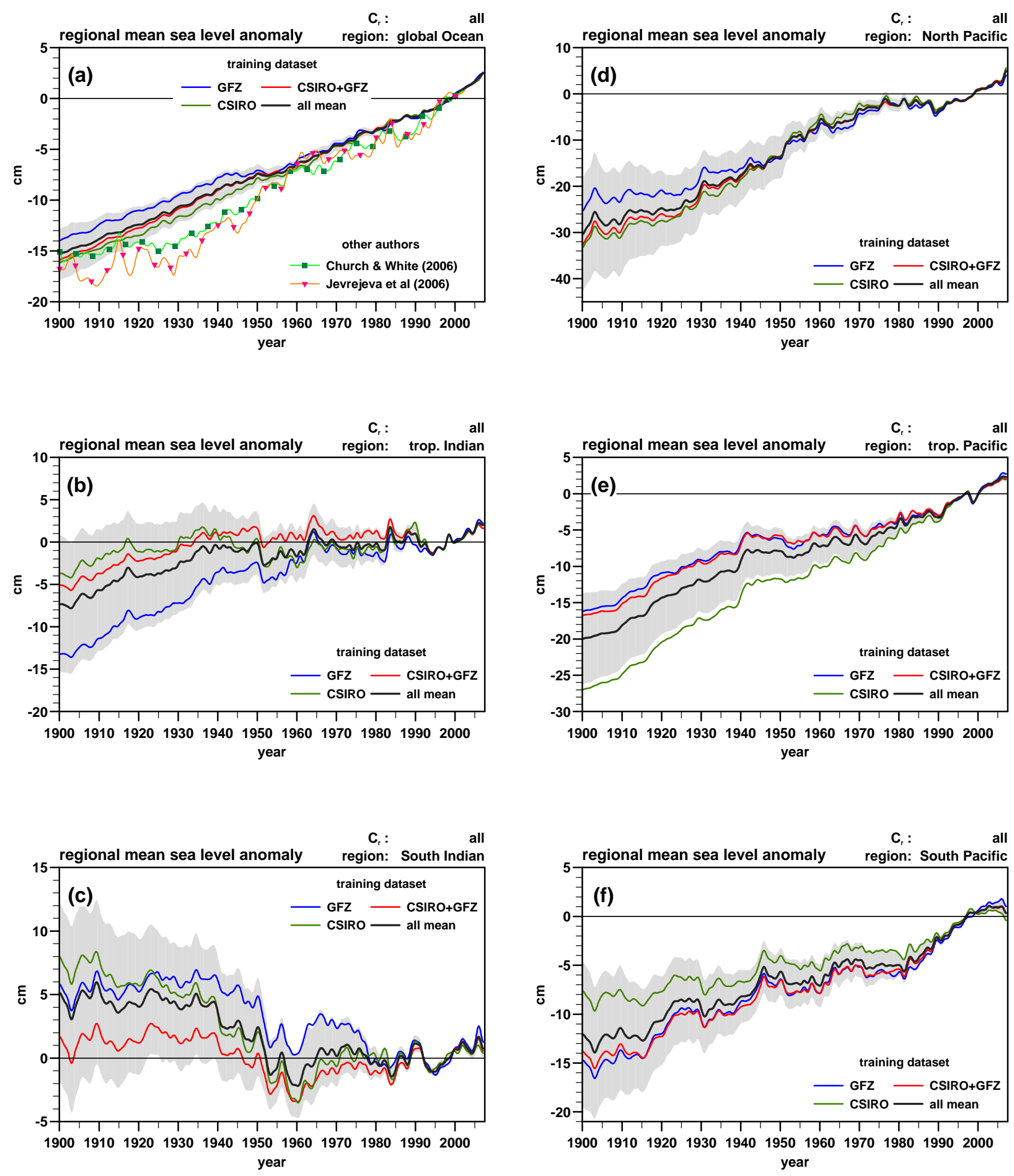

Figure 11. ... continued on next page! 

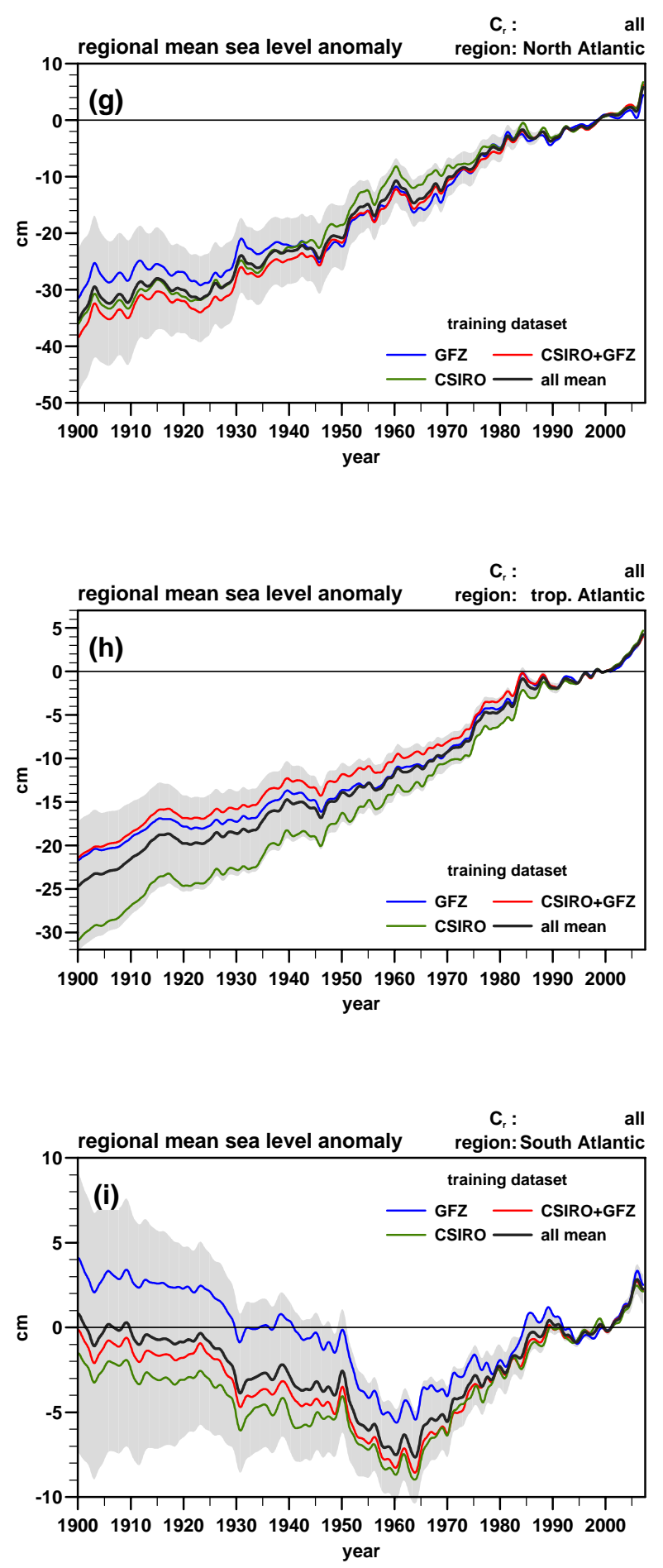

Figure 11. ... continued 

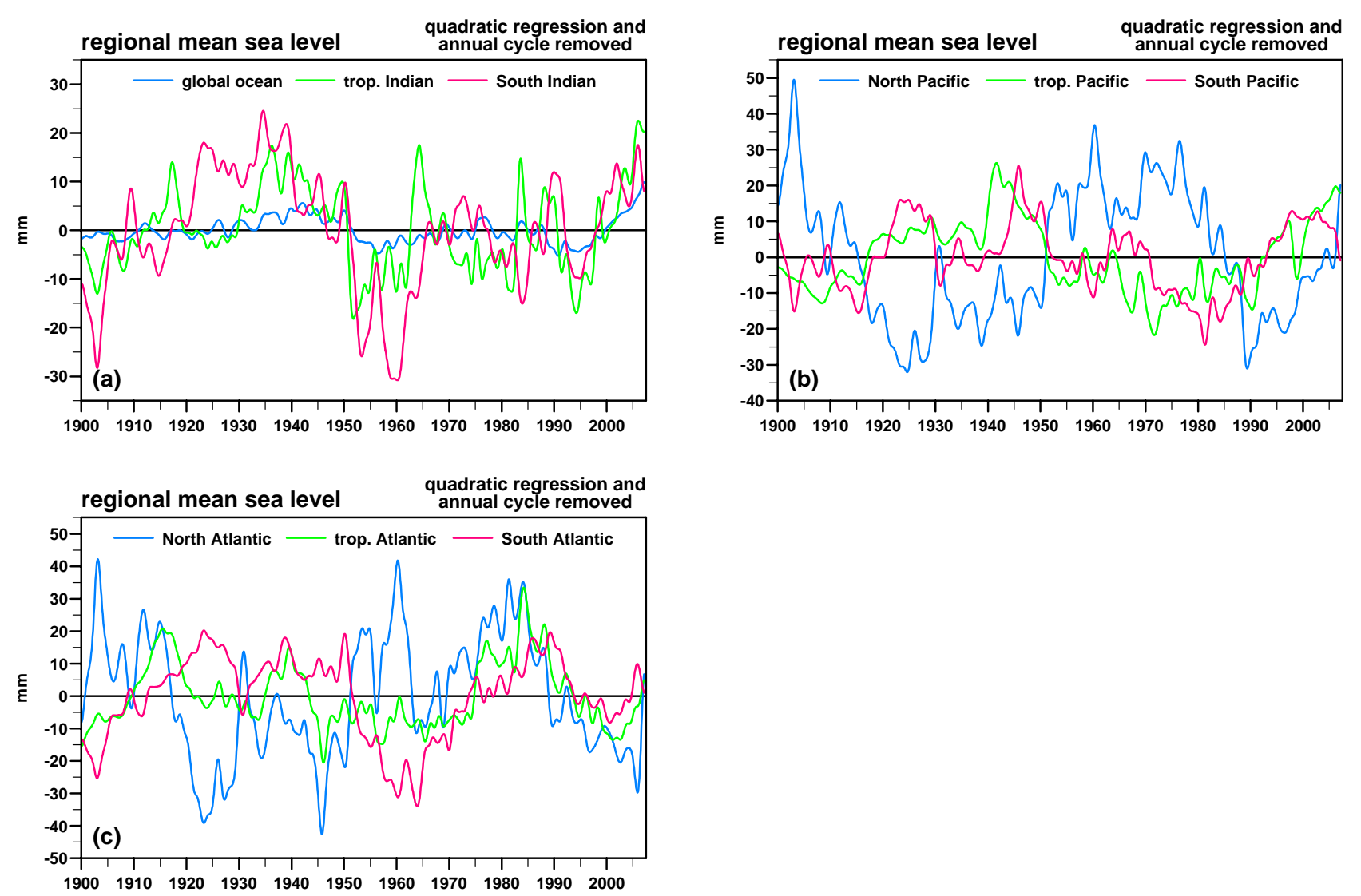

Figure 12. 

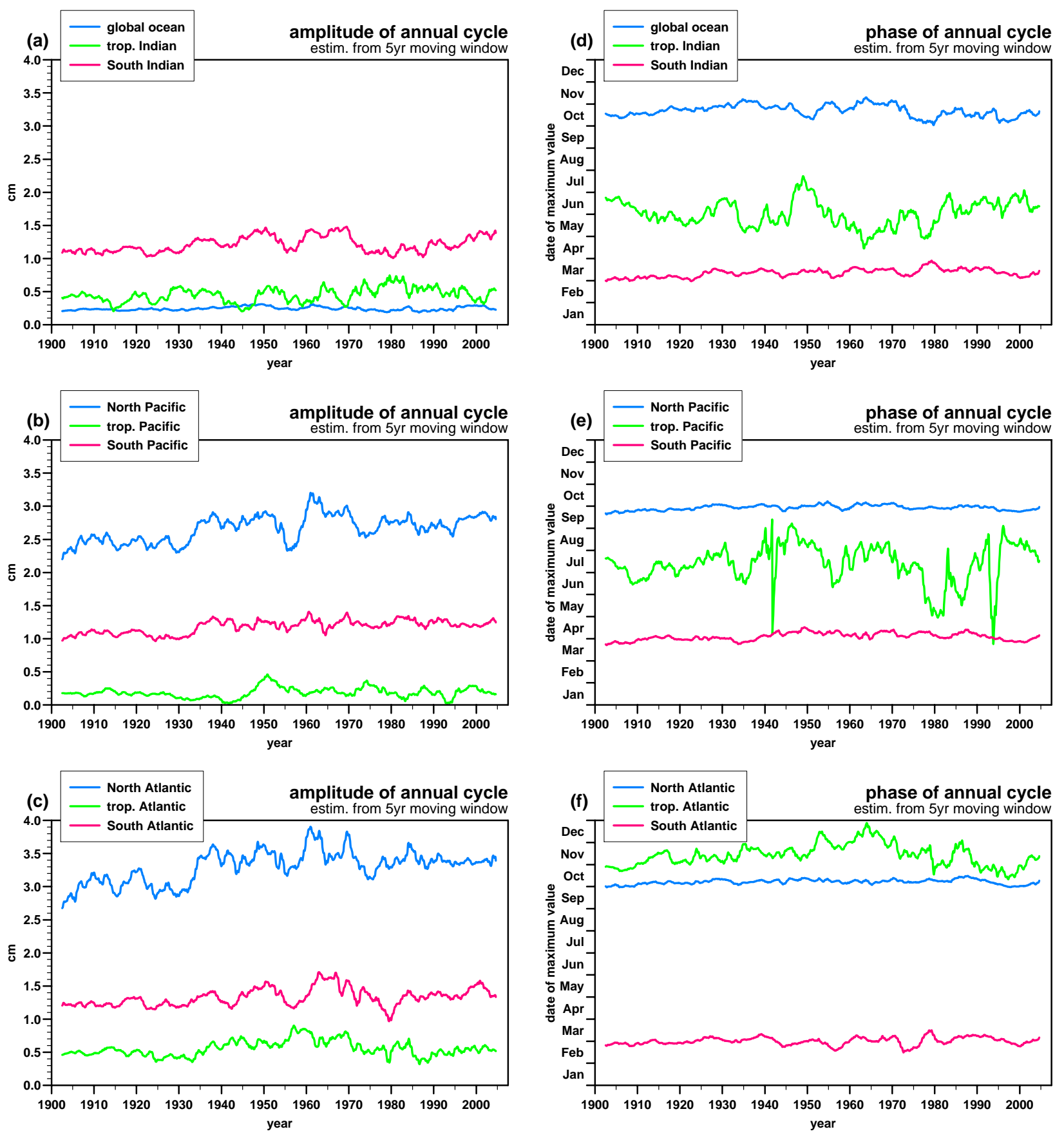

Figure 13. 